\title{
LOS PSEUDÓNIMOS DE UNA EXCEPCIÓN O FILOSOFAR DESPUÉS DE KIERKEGAARD SEGÚN PAUL RICOEUR
}

\author{
Luz AscáraTe
}

Pontificia Universidad Católica del Perú

Resumen: Paul Ricoeur, lector de paradojas, interpreta la filosofía kierkegaardiana de forma paradójica en dos sentidos. El primer sentido hace referencia a aquella paradoja en el exterior de su filosofía y está representada por sus pseudónimos. Desde este punto de vista, Kierkegaard, el existente, es la excepción de sus pseudónimos y, con ello, representa la paradójica relación de todo filosofar con la existencia particular que es el filósofo, existencia que representa la no-filosofía, fuente de todo filosofar. El segundo sentido apunta al interior de su filosofía, en tanto sus desarrollos conceptuales representan el inacabamiento del sistema filosófico al tratar la temática del mal como enigma irresoluble que se tematiza en el centro de la existencia como angustia y desesperación. A partir de esta lectura formulamos la pregunta ien qué consiste filosofar después de Kierkegaard?, y respondemos: consiste en filosofar más allá de la filosofía misma, a partir y con la existencia que nutre el filosofar, propiciando el tratamiento irresoluble del proceder filosófico.

Palabras clave: Kierkegaard, Ricoeur, paradoja, no-filosofía, existencialismo

Abstract: Paul Ricoeur, known as a reader of paradoxes, interprets Kierkegaard's philosophy "paradoxically" in two ways. This exception represents the paradoxical relationship of all philosophical work with the particular existence that is the philosopher, existence that must be understood as the non-philosophical source of every philosophy. The second one refers to the inside of his philosophy. In this sense, his conceptual developments represent the incompleteness of the philosophical system when it has to deal with the issue of evil: an unsolvable enigma that is thematized at the center of existence as anguish and despair. From this point of view, we formulate the question: "how can we understand the philosophical work after Kierkegaard?", and our answer claims that this meaning goes beyond philosophy itself. It consists 
in starting at the existence that nourishes philosophy, and enables the never-ending treatment of philosophical procedure.

Keywords: Kierkegaard, Ricoeur, paradox, non-philosophy, existentialism

El presente texto está dedicado a una particular concepción del filosofar: aquella que tiene como punto de partida a la filosofía de Kierkegaard, desde la lectura que hace de ella Paul Ricoeur. Este último, pensador de paradojas, encuentra en Kierkegaard, la máxima representación de la paradoja que es propiamente la filosofía, puesto que el filosofar de Kierkegaard nos lleva a aquel aspecto de Kierkegaard que no puede ser seguido ni desde el filósofo ni desde el teólogo: a su existencia incomunicable. Pero si es que hay una parte de Kierkegaard que sí puede seguirse, por pertenecer a la argumentación filosófica, a la reflexión y a la especulación, "esta parte está representada por los pseudónimos"291. En ese sentido, "no podemos filosofar después de Kierkegaard, pero quizás después de sus pseudónimos en la medida en que ellos pertenecen a la misma esfera filosófica que el idealismo alemán”292.

Ahora bien, la paradoja del filosofar kierkegaardiano tiene, para Ricoeur, dos aspectos. De un lado, Kierkegaard se encuentra realmente fuera de la filosofía y de la teología. Este primer lado de la paradoja es, por decirlo así, del lado exterior de la filosofía en el que se encuentra Kierkegaard, el existente. La pregunta a la que ello nos enfrenta es la pregunta por la genialidad, según Ricoeur, "como fuente no filosófica de la filosofía" ${ }^{293}$. En el caso de Kierkegaard, esta genialidad se encuentra no solamente en el Kierkegaard real, sino también en el mítico, creado por sus propias historias: "Todo el mundo acuerda que la novela de su existencia efectiva constituye algo único en la historia del pensamiento: el dandy de Copenhague, el extraño novio de Regina, el soltero de la astilla en la carne, el insoportable censor del conde Mynster, la dolorosa víctima del Corsario, el que agoniza en el hospital público"294.

291 Ricoeur, P., "Philosopher après Kierkegaard”, en: Ricoeur, P., Lectures 2. La contrée des philosophes, Paris: Seuil, 1992, p. 32.

292 Ibid.

293 lbid. 
Ni Kierkegaard ni ninguno de estos personajes puede ser comprendido: Kierkegaard es la excepción de sus personajes reales. Para Ricoeur, así también, Kierkegaard es el único que ha podido representar su propia biografía en una especie de mito personal por su identificación con sus personajes fantásticos: Abraham, Job, Ahasvérus, entre otros. Esta existencia poética disimula su existencia real: Kierkegaard es la excepción de sus personajes ficticios. Y, a la vez, es un personaje creado por sus propias obras, "un autor, hijo de sus obras, un existente que se irrealiza a sí mismo y se sustrae a cualquier disciplina conocida"295. Ello porque no pertenece a sus propios "estados del camino de la vida": "no fue lo suficientemente don Juan, ni lo suficientemente seductor para ser esteta, no logró ser hombre de ética, ni esposo ni padre"296: Kierkegaard es la excepción de sus categorías.

Comprender a Kierkegaard es, en ese sentido, no comprender sus conceptos o categorías. Es dejarlo de lado, fuera de la filosofía, fuera de la teología: "dejarlo ser lo que es; no sirve de nada corregirlo, refutarlo, completarlo" ${ }^{297 .}$ Según Ricoeur, además, realmente nunca lo refutamos ni lo completamos, así nos lleva a lo realmente importante del filosofar: "lo leemos, lo meditamos, y cumplimos su tarea con 'la mirada fija en la excepción””298. Ricoeur está pensando en que, con Kierkegaard, se cumple el precepto de Jaspers: "La tarea que nos corresponde, a nosotros que no somos la excepción, es la de filosofar con la mirada fija en la excepción" 299 .

Según Ricoeur, tener la mirada fija en la excepción significa redescubrir la relación íntima de toda filosofía con la no-filosofía: "La filosofía ha tenido siempre que ver con la no-filosofía, porque la filosofía no tiene objeto propio. Ella reflexiona sobre la experiencia, sobre toda experiencia, sobre el todo de la experiencia: científica, ética, estética, religiosa. La filosofía tiene sus fuentes fuera de ella misma. Digo sus fuentes, no su punto de partida; la filosofía es responsable de su punto de partida, de su método, de su cumplimiento; la filosofía busca su punto de partida; ella va hacia su punto de partida (...). Pero si busca su punto de partida, recibe sus fuentes; dispone de su punto de

295 Ibid., p. 33.

296 Ibid.

297 Ibid., p. 34.

298 Ibid.

299 Ricoeur, P., “Kierkegaard et le mal”, en: Ricoeur, P., op. cit., p. I5. 
partida, no dispone de sus fuentes, es decir de aquello que la abastece y la instruye en la base" ${ }^{300}$. Esta enseñanza es la que yace implícita en la figura de Kierkegaard en tanto "la excepción Kierkegaard, el genio retórico-religioso, el dandy martyr no constituyen una situación única”.

El otro aspecto de la paradoja es del lado interior de la filosofía. El lado interior de la filosofía de Kierkegaard no es, como mostramos, el del Kierkegaard existente, sino el de sus pseudónimos, pero justamente ello hace posible que podamos filosofar después de él: "si Kierkegaard se encuentra al exterior de la filosofía, Constantino Constantius, Johannes de Silentio, Virgilius Haufniensis, son autores filosóficos" ${ }^{301}$. El problema que ve aquí Ricoeur es el de la comunicación indirecta "y la comunicación indirecta, a su vez, reposa sobre un modo propio de argumentación" 302 . En ese sentido, sus pseudónimos constituyen una argumentación filosófica que, además, crea conceptos (el de la angustia, la desesperación, el pecado), y construye una antidialéctica que, para Ricoeur, se elabora sobre el terreno mismo de la dialéctica hegeliana: "la paradoja es aún una estructura lógica, la que conviene al tipo de demostración requerida por la problemática del existente, del individuo delante de Dios" ${ }^{303}$. Considera, en este sentido, Ricoeur al Post-Scriptum como la obra más extraordinaria de la filosofía kierkegaardiana: "Es toda una red de categorías que se despliegan: la eternidad, el instante, el individuo, el existente, la elección, lo único, la subjetividad, el delante de Dios, el absurdo"304. Y ello, continúa Ricoeur, "no es más la no-filosofía, es la hiper-filosofía llevada hasta la caricatura y la burla" ${ }^{305}$. Es en este nivel en el que sitúa el problema de la lógica del discurso kierkegaardiano: en las categorías del existente.

Ello se comprende si situamos la radicalidad de la filosofía de Kierkegaard como la cara opuesta de otra radicalidad: el de la sistematicidad hegeliana. Mientras que la primera es una paradoja sin mediación, la segunda es mediación, síntesis, reconciliación. Ambas tienen una lógica contrapuesta y en ese sentido una se

300 Ricoeur, P., "Philosopher après Kierkegaard”, p. 34.

30 I Ibid., p. 35.

302 lbid., p. 36.

303 lbid.

304 lbid.

I40 305 Ibid. 
comprende desde la otra. Así pues, Ricoeur opone la existencia al sistema para pensar la lógica del discurso filosófico kierkegaardiano.

En otro artículo de Ricoeur ("Kierkegaard y el mal"), se aborda justamente esta radicalidad a partir de la cuestión del mal: "Vale la pena señalar que el mal es el punto crítico de todo pensamiento filosófico: si lo comprende, es su más grande éxito; pero el mal comprendido no es más el mal, ha dejado de ser absurdo, escandaloso, fuera de derecho y de razón. Si no lo comprende, entonces la filosofía no es más filosofía, si la filosofía debe al menos comprenderlo todo y erigirse en sistema sin mantenerse fuera de sí”306.

En el gran debate entre Kierkegaard y el sistema que representa la figura de Hegel, cree Ricoeur, "la cuestión del mal representa una incomparable piedra de toque" ${ }^{307}$. Los dos textos a los que se avoca para reconstruir el problema del mal en Kierkegaard son El concepto de la angustia y La enfermedad mortal. Ambos tienen en común que tienen por base dos sentimientos negativos cuyo objeto es indeterminado: "la angustia, la desesperación. ¿La angustia de qué? ¿La desesperación de qué?" ${ }^{308}$. Ricoeur no quiere aquí partir, buscando hacer justicia a Kierkegaard, de una definición moral del mal como culpabilidad o transgresión de alguna ley, lo que se quiere es descubrir una dimensión de pecado anunciada en aquellas profundas emociones ${ }^{309}$. Tal dimensión no es ética, sino religiosa.

No hay duda de que La enfermedad mortal, de Anti-Climacus, es un ensayo psicológico. Leemos en el subtítulo “Una exposición cristiano-psicológica para edificar y despertar" ${ }^{\prime 10}$. Este habla del mal, según Ricoeur, como un estado de cosas, como algo que in-siste, a diferencia de El concepto de la angustia que habla del mal como un acontecimiento, como un salto: "la angustia tiende hacia" ${ }^{\prime \prime}$, "la angustia 'ex-siste"”312. La desesperación revela al pecado como un estado:

306 Ricoeur, P., “Kierkegaard et le mal”, p. 16.

307 lbid.

308 Ibid., p. 17.

309 Cf. ibid.

310 Kierkegaard, S., La enfermedad mortal, traducción de Demetrio Gutiérrez Rivero, Madrid: Trotta, 2008.

3II Ricoeur, P., “Kierkegaard et le mal”, p. 20.

312 lbid. 
"no podemos decir: la angustia es pecado; podemos decir: la desesperación es pecado"313. El pecado es, además, nuestra manera ordinaria de ser delante de Dios"314; en ese sentido, es determinación del existente.

El camino que sigue Kierkegaard para reconstruir el concepto de desesperación en este tratado evidencia, según Ricoeur, la contraparte de la dialéctica hegeliana: "Reemplaza una dialéctica de tres términos por una dialéctica herida, por una dialéctica no resuelta en dos términos. Una dialéctica sin mediación, tal es la paradoja kierkegaardiana. $O$ bien demasiada posibilidad, o bien demasiada actualidad; o bien demasiada finitud, o bien demasiada infinitud; o bien se quiere ser sí mismo, o bien no se quiere ser sí mismo. Además, como cada par de contrarios no ofrece una resolución, no es posible edificar la paradoja siguiente sobre aquella que la precede; la cadena de paradojas es ella misma una cadena rota; donde el cuadro dialéctico, substituye a la estructura inmanente de una verdadera dialéctica; la ruptura que amenaza este discurso debe ser siempre conjurado, compensado por un aumento de conceptualización y de habilidad retórica; de donde el singular contrasta: es el termino más irracional-la desesperación-que pone en movimiento la más grande masa de análisis conceptuales"315.

Así mismo, en su reconstrucción del concepto de angustia, Kierkegaard afirma: "Si queremos, pues, considerar las definiciones dialécticas de la angustia, resulta que tienen realmente la ambigüedad psicológica. La angustia es una antipatía simpatética y una simpatía antipatética" ${ }^{316}$. Preguntamos: ino evidencia ello tal dialéctica sin mediación? Kierkegaard responde: "Ahora bien, como la relación de la angustia con su objeto es algo que no es nada -el lenguaje usual dice, en efecto, exactamente: angustiarse de nada- es sumamente ambigua, la transición que puede recorrerse aquí desde la inocencia a la culpa se torna justamente tan dialéctica, que resulta patente: la explicación es lo que debe ser, psicológica. El salto cualitativo destácase netamente sobre la ambigüedad del estado anterior. Pues quien se hace culpable por angustia es inocente: no fue él mismo, sino la angustia, un poder extraño que hizo presa en él, un

\footnotetext{
313 Ibid., p. 26-27.

314 Ibid., p. 27.

315 Ibid., p. 23.

316 Kierkegaard, S., El concepto de la angustia, traducción de José Gaos, Madrid: Revista de
} 142 Occidente, 1930, p. 66. 
poder que él no amaba, del cual, por el contrario, se apartaba angustiado; $y$ sin embargo es culpable: se habría hundido en la angustia, a la que amaba a la vez que temía. No hay en el mundo nada más ambiguo que esto, y por ello es ésta la única explicación psicológica”317.

La psicología corresponde, aquí, a la mostración de la ambigüedad que es la angustia y, más radicalmente, a la radicalidad que es la existencia: "¿Qué relación guarda el espíritu consigo mismo y con su condición? -El espíritu tiene angustia de sí mismo"318.

De este modo, según Ricoeur, Kierkegaard posibilita la reflexión sobre la negatividad, que es el mal, el pecado, la angustia, la desesperación, sin mediación ni solución: es en ese ámbito en el que yace la genialidad filosófica a la que se enfrenta el discurso filosófico. Ello no empaña la pulsión sistemática de la filosofía, sino que la hace posible: "La filosofía está en debate con Kierkegaard como con todo genio no filosófico; su tarea propia sigue siendo buscar el principio o el fundamento, el orden o la coherencia, la significación de la verdad y de la realidad: su tarea es reflexiva y especulativa"319.

Podemos decir con Ricoeur que filosofar después de Kierkegaard es, finalmente, considerar que "la filosofía está siempre en relación con la no-filosofía. En ese sentido, el lado irracional de la experiencia de Kierkegaard es una fuente de la filosofía a título de toda genialidad. Si se corta el nexo vital entre filosofía y no-filosofía, la filosofía corre el riesgo de no ser más que un simple juego de palabray, en última instancia, un puro nihilismo lingüístico" ${ }^{220}$. Filosofar después de Kierkegaard es, a su vez, pensar a la filosofía a partir de la imposibilidad de la construcción del sistema: la paradoja, la anti-dialéctica, la irresolución, o lo que es lo mismo, pensar al absoluto desde la existencia.

\footnotetext{
317 Ibid., p. 67.

318 lbid.

319 Ricoeur, P., "Philosopher après Kierkegaard", p. 35.

320 lbid., p. 44.
} 